\title{
Epidemiological Aspects of Hepatitis C in Brazil
}

\author{
Decio Diament \\ Emílio Ribas Institute of Infectious Diseases; São Paulo, SP, Brazil
}

The true dimension of the epidemiological situation of chronic hepatitis $\mathrm{C}$ in Brazil remains unknown. According to data from the National Ministry of Health, 52,489 cases were diagnosed in the period from 1994 to 2005 . However, the data regarding the final year of this series are incomplete. There is a trend toward an increase in the number of diagnosed cases during this period, since diagnostic techniques have become more widely available, both in public and private health care facilities (Figure 1).

Figure 1. Number of diagnosed cases of hepatitis C reported by the National Ministry of Health, from 1994 to 2005, totaling 52,489 cases.

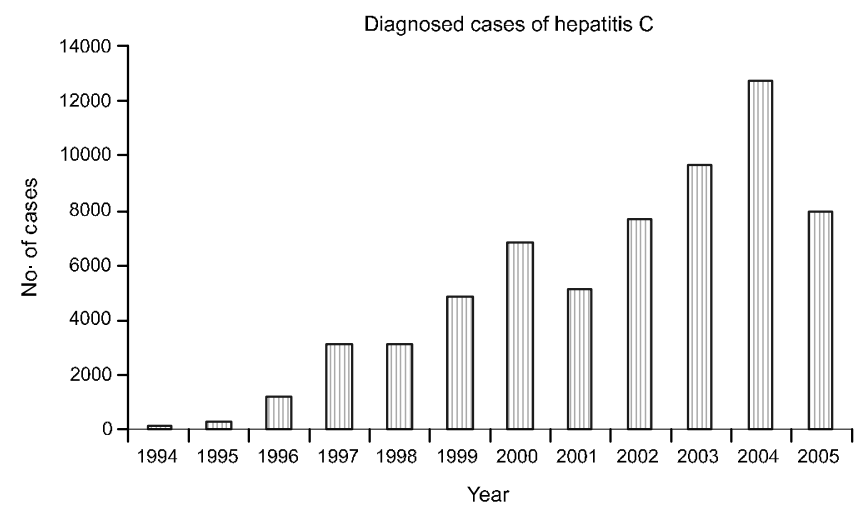

Most diagnosed cases occur in the Southeast, followed by the South, Central-west, Northeast and North (Figure 2).

Figure 2. Distribution of cases by macroregion (National Ministry of Health).

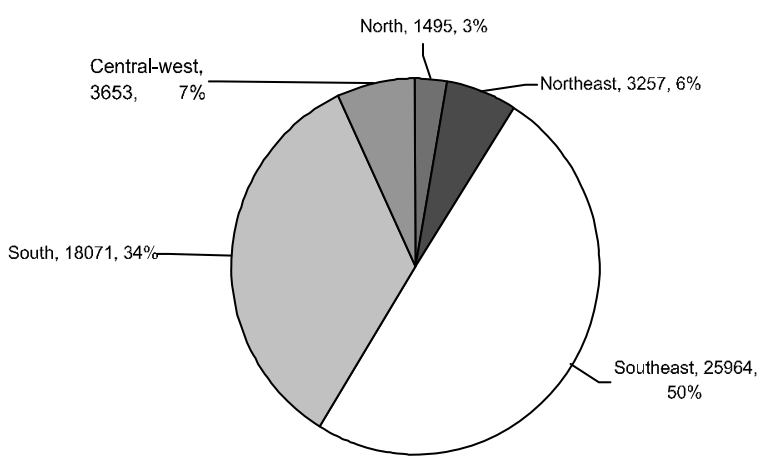

The Brazilian Journal of Infectious Diseases 2007;11 (5) Suppl. 1:6-7. (C) 2007 by The Brazilian Journal of Infectious Diseases and Contexto Publishing. All rights reserved.
This distribution reflects the greater availability of resources as well as the highly populated areas in the southeastern and southern regions of the country. However, serological surveys carried out in the Central-west and Northeast, as well as in the Federal District, showed prevalence rates similar to those of a previous survey carried out in the city of São Paulo (Figure 3).

Figure 3. Prevalence of hepatitis $\mathrm{C}$ in serological surveys in several regions of the country (Galizzi Filho J, personal communication, for the data of the surveys on the Centralwest, Federal District and Northeast; Focaccia R., personal communication, for the data on São Paulo).

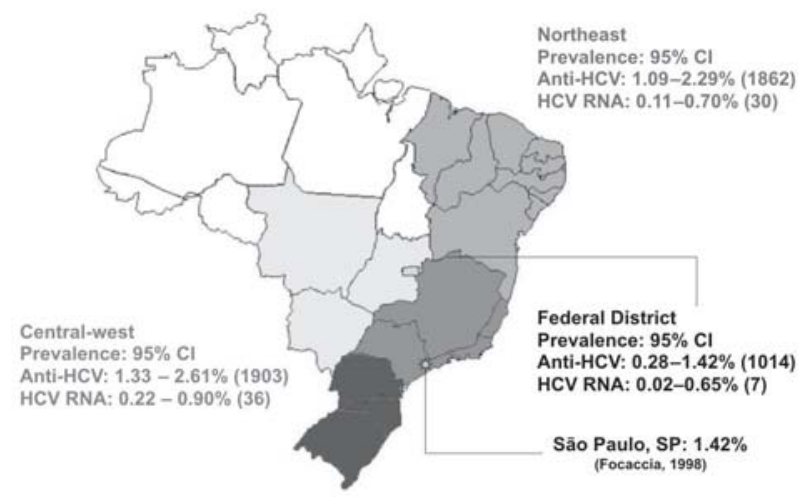

Data obtained in these serological surveys indicate prevalence rates from 0.28 to $2.61 \%$. According to the 2000 census taken by the Brazilian Institute of Geography and Statistics, Brazil has a population of approximately 170 million. It has been shown that, of those testing positive for infection with the hepatitis $\mathrm{C}$ virus ( $\mathrm{HCV}$ ), approximately $80 \%$ have the chronic form of hepatitis $\mathrm{C}$. Based on these data, we can estimate that there are 400,000 to 3,800,000 cases of chronic hepatitis $\mathrm{C}$ in Brazil. Comparing these numbers with the data from the National Ministry of Health, we can conclude that there are a great number of undiagnosed cases of the disease. Since there has been a trend toward an increase in the number of diagnosed cases, there will be a significant increase in the demand for diagnosis and treatment of chronic hepatitis $\mathrm{C}$ in the future.

Another interesting fact is that only 17,204 (33\%) of the 52,493 cases of chronic hepatitis reported to the Center for Epidemiological Surveillance of São Paulo, from 1998 to 2006, were confirmed as being hepatitis C. Another 10,690 cases (20\%) were classified as inconclusive for hepatitis C, 2099 (4\%) were excluded, and 416 (0.79\%) were cases of $\mathrm{HBV} / \mathrm{HCV}$ co-infection. The remaining cases were confirmed as hepatitis $\mathrm{B}, \mathrm{HBV} / \mathrm{HDV}$ co-infection, or cases under investigation. 
Of the 17,204 confirmed cases, the principal form of contamination was parenteral (use of injected illicit drugs, as well as blood and blood product transfusions), followed by sexual transmission. Work-related accidents accounted for few of the cases (Figure 4).

Figure 4. Distribution of cases of chronic hepatitis C by form of transmission in 17,204 individuals in the state of São Paulo, from 1998 to 2006 (Source: Center for Epidemiological Surveillance, São Paulo).

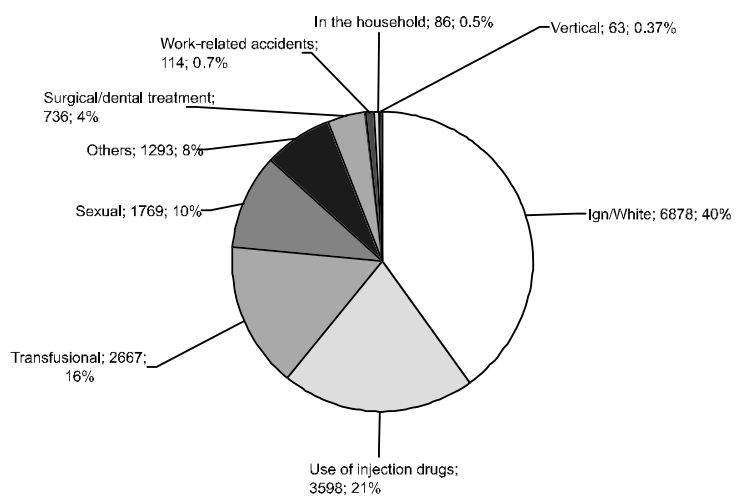

Transmission was classified as unknown in $40 \%$ of the reported and confirmed cases, as can be seen in Figure 4. This suggests that the investigation of the form of transmission should be improved, and that items such as administration of medication using nondisposable syringes, acupuncture, tattoos, and piercings should be included in the epidemiological investigation. Another unusual fact is sexual transmission in $10 \%$ of the cases, well above the expected, which is less than $1 \%$.

Another aspect to be considered is the occurrence of hepatitis $\mathrm{C}$ in groups of differentiated risk, that is, unusual cases such as those described in Figure 4. The first group would be that of the manicurists, since it is supposed that the community use of instruments by these professionals would expose them to a higher risk of contamination. There is no evidence that this could happen, and a recent serological survey conducted in the city of São Paulo in beauty salons located at shopping malls in various neighborhoods did not demonstrate prevalence rates different from those of the population in general (Oliveira, ACDS - personal communication).

Another group is that of the dentists. In Brazil, localized serological surveys with small samples of patients have shown a low prevalence rate, ranging from 0.4 to $0.7 \%$. However, a study on the level of knowledge of these professionals about the disease has shown it is very low, demonstrating the need of greater emphasis on training and continuing education, aiming at making them capable of properly protecting themselves, as well as of preventing transmission to patients and perhaps even help the diagnosis, since several extrahepatic manifestations appear in the mouth cavity, such as oral liquen planus, erythema nodosum, etc.

\section{References}

1. Bellíssimo-Rodrigues W.T., Machado A.A., Bellíssimo-Rodrigues F., et al. Prevalence of hepatitis B and C among Brazilian dentists. Infect Control Hosp Epidemiol 2006;27:887-8.

2. h t t p : / / p orta l. saud e.gov. br/port a l/s a ude / visualizar_texto.cfm?idtxt=25340. Acessado em 24/08/2007.

3. http://www.cve.saude.sp.gov.br/htm/hepa_home.html. Acessado em 24/08/2007.

4. Leão J.C., Teo C.G., Porter S.R. HCV infection: aspects of epidemiology and transmission relevant to oral health care workers. Int J Oral Maxillofac Surg 2006;35(4):295-300.

5. Takahama A.J., Tatsch F., Tannus G., Lopes M.A. Hepatitis C: incidence and knowledge among Brazilian dentists. Community Dent Health 2005;22(3):184-7. 